\title{
Comparison of the Present Situation Investigation and Folk Custom in Qujing Area of the Miao Nationality
}

Yu Chen

School of Music and Dance, Qujing Normal University, Qujing, Yunnan, China

Abstract - Miao is a migration of nationality, whose history can be said to be a history of migration, the area of Qujing Miao mostly moved from Guizhou and settled, andbreed here so far, in the long run the migration process after neutralization settled in Qujing area Miao minority has formed many folk characteristics different from other regions, taking Qujing area as the main research object of the Miao nationality. conducted a survey on the origin and the status quo, compares the folk custom, the ultimate importance of protected.

Keywords-Miao, Qujing area, folk contrast, protection

\section{曲靖地区苗族的现状调查与民俗对比}

\author{
陈 郁
}

曲靖师范学院音乐舞蹈学院, 曲靖, 云南, 中国

\begin{abstract}
摘 要 苗族是一个迁徙的民族, 他的历史可以说是一部迁徙史, 曲靖地区的苗族大多是从贵州迁入定居, 并在此繁衍生息至今 的, 在迁徙的过程中和定居后的长期生活中，曲靖地区的苗族形成了许多有别于其他地区的民俗特征，文章以曲靖地区的苗族作为主 体研究对象，对源流和现状进行了调查，把民俗进行了对比，最终阐述加以保护的重要性。
\end{abstract}

关键词 苗族, 曲靖地区, 民俗对比, 保护

\section{1. 引言}

苗族是云南曲靖地区除布依族、彝族、水族、回族、 瑶族、壮族外的七种世局少数民族之一，在曲靖下辖的一 区一市七县中, 有宣威、马龙、师宗、罗平、会泽、沾益 共六个县份分布有苗族, 苗族是一个不断迁徙流动的少数 民族, 曲靖的苗族大多都是陆续由贵州迁徙而来, 有些继 续迁徙, 有些就分散定居在了曲靖的各个县份, 繁衍生息 至今, 逐渐形成了与其他地区苗族不同的民族风俗。

\section{2. 曲靖各地区苗族的源流及概况}

宣威的苗族从贵州威宁迁徙而至的历史, 据 1825 年《宣 威州至》卷五第43页记载, 至今已有一百多年的历史了, 有家谱传说记载甚至更早, 因为封建地主的压迫剥削, 苗 族没有固定的居所, 一直都过着游民迁徙的生活, 因此, 很难准确查到宣威苗族迁徙而至的确切时间。现今宣威苗 族多以大分散、小聚居的形式在县内西北方的高寒山区或 半山区, 主要聚居地为倘塘、西泽、热水三个乡镇, 全县
2003 年末, 有人口 4271 人。

马龙地区的苗族大部分是在明清之际, 由赫章、牟定、 威宁、宣威等地逐渐迁徙而来的, 也有少部分一些是从东 川迁入的。现今, 这些马龙的苗族主要分布定居在象山、 木龙、后山、砍斧箐、大地头、轿子山、赵家庄、干冲、 落水洞、长凹子、朱家大箐、大石岩、上下西冲等 40 余个 村庄, 人口由 1964 年的 1169 人, 逐渐增长为 2003 年的 3807 人。苗族内部的自称和分支众多, 马龙县内的苗族人大部 分都属于大花苗支系，自称为“大花苗”或“阿蒙”。

师宗县是师宗民俗风情浓厚, 境内居住着壮族、彝族、 苗族、瑶族、回族 5 种少数民族 6 万余人, 少数民族人口占 全县总人口的 $17.14 \%$, 少数民族比例居全市第一, 素有“十 里不同族, 五里不同俗”之说。高良瑶族苗族自治乡是师宗 三个少数民族自治乡之一, 是师宗最为集中的苗族聚集乡。

罗平县相比曲靖其他地区苗族入境定居稍晚一些, 据 史料和传说记载, 大约在清代中叶, 陆续由贵州、四川等 地迁徙至文山直至东南亚地区的过程中, 少部分留在了罗 
平县境内定居下来, 主要分布在鲁布革乡、大水井乡、旧 屋基乡、环城乡等地的山区， 2000 年 11 月人口普查有 4268 人。罗平县的苗族主要是白苗和花苗两个支系。

会泽的苗族迁徙繁衍至今约有九十余年历史了, 均是 由贵州威宁迁徙而来的, 多散居在大井、马路、田坝 3 个乡, 现有 $238 户, 975$ 人。会泽县内的苗族与贵州威宁等地一样 同属大花苗支系。

沾益县的苗族是明清时期开始至民国初年, 陆续由贵 州威宁、云南宜良、宣威等地迁入的，1950年后，威宁、 宣威、马龙依然有苗族不断迁入, 沾益县除播乐乡外的九 个乡镇都有苗族散居, 主要分布在老麻沟、独石山、大坡 乡的小海新联等村, 花山镇三道坎村是全县居住最为集中、 人口最大的苗族聚集村，全村 116 户，共 464 人。沾益的苗 族自称“阿卯”或“阿卯老”, “阿”为前缀, 没有实际语义, “卯” 为“苗”的意思, “老”为“花”之意, 寓意“我是花苗”, 他称“大 花苗”。

\section{3. 曲靖地区苗族的语言文字}

苗族是少数拥有本民族语言文字的民族之一, 苗族语 言属于汉藏语系苗瑶语族苗语支, 因苗族迁徙频繁, 分为 湘西、黔东、川滇黔三个方言区, 七个次方言, 十八种土 语, 苗族长期分散在西南各地, 因此方言差异较大, 曲靖 地区的苗语属于川西部方言中的滇东北次方言, 现在曲靖 地区的苗族使用苗语和汉语两种语言交流, 苗族聚集村镇 上的小学学校里, 实行的是汉苗双语文教学。

史籍中苗文有“刻木为契”的记载，曲靖地区没有发现。 民国前夕, 英国基督教传教士坡拉德 (汉名伯格里), 与苗 族教师杨雅名、李探文等在滇黔一带传教, 依据滇东北次 方言苗语，用坡拉字母创造了一套拼音文字，称之为“坡拉 字母苗文”，俗称“老苗文”，用来传播基督教的教义，1906 年使用后, 一直在滇东北苗家盛行, 沿用到了五十年代中 期。1956年以后, 由原中国科学院少数民族语言调查第二 工作队, 对苗语进行了系统的调查研究, 创制出了苗文, 经过四十年的实践，深得苗族人民的喜欢。

\section{4. 曲靖地区苗族民俗的对比}

曲靖地区的苗族多是由贵州迁徙而至的, 但是随着居 住环境的改变和历史的变迁，曲靖地区的苗族逐步形成了 与贵州地区有所不同的, 具有自己独特习俗习惯的民俗特 征。
4.1 服饰

苗族的服饰女装款式有很多，大体可以分为两大类: 第一类是传统的古老样式，上着大领或大襟衣，下着百褶 裙, 头饰多数挽椎䯽扎于头顶, 配饰丰富华丽大方; 另一 类是盼头包头巾, 上着大襟衣, 下配长裤, 衣缘、衣袖、 两肩、胸前、裤脚都镶或绣有“花边”，多用青色、蓝色、 黑色。男装都上穿对襟或左大襟短衣, 下穿长裤, 系大腰 带, 头裹青色长巾。

曲靖地区的服饰有所不同，在清朝时期，因民族暴动 失败后，被迫改装，女装的基本款式为上着对襟或大襟短 衣，一部分有后披领，下着有分截的长裙或长裤，前面系 有围裙, 后面垂有飘带, 其它部分还有花披肩, 男人则穿 戴有花纹的麻布衣服，肩披羊毛段。

\section{2 建筑}

苗族多居住在山区，山高坡陡，潮湿多雾，不适宜建 造砖房或瓦房, 因此在坡度比较大的山坡, 苗族人多建造 一种通风性能较好的瓦木或木质结构的吊脚楼。较大型的 苗寨, 还有非常具有民族特色的公共寨门, 公用水碾和水 车等。

曲靖地区苗族建造的房屋多为叉叉房, 是土木或草木 构成的平房，屋架多用不剥皮的树杆和树枝交绑组成，四 壁和屋顶夹茅草, 有的围以竹篱笆, 具有因地制宜, 就地 取材营造而成的特点。

\section{3 婚姻}

苗族年轻人通过“游方”社交活动、自由对歌、恋爱成 婚, 同姓之间是不能结婚的, 实行的是一夫一妻制, 丧偶 方可再娶或再嫁，若夫妻不和也可离婚。婚后女方有两种 情况, 一种是新娘长期居住夫家，一种是结婚后当天或次 日即回娘家，除节日农忙或家中生大事，才在男方家住一 段时间。苗族婚嫁最大的特点就是自由恋爱、婚姻自主, 父母一般不加干涉。

曲靖地区苗族在建国前是不与外族通婚的, 男方请的 媒人要去女方家说三次媒, 婚姻形式有两种, 一种男娶女 方的“讨娶”; 一种男入女方家的“招婿上门”。女方嫁到婆 家后, 不许上婆家的楼, 要用什么东西, 要请男方的兄弟 姐妹去拿，只有分了家以后，才能自己上自己的楼。

4.4 宗教信仰

苗族一般多信仰原始宗教，多神信仰，有自然崇拜、 
造物崇拜和祖先崇拜等, 属于敬天地信鬼神万物有灵的原 始宗教, 最为神圣的是祭祖仪式, 和祈求神灵驱除病魔的 祭门猪仪式。

曲靖地区苗族的宗教信仰比较特殊, 在民国前夕传入 了基督教, 使很多苗族因此受益, 改信基督, 特别是马龙 县内主要分布的王家庄、马鸣、月望三个乡镇, 有三个分 支的基督教, 信徒主要都是苗族。

\section{5．加强地区苗族民俗文化保护的重要性}

苗族是一个古老的民族, 有着悠久的民族文化和 历史遗产, 应当受到保护、传承和发扬。然而现今苗族 民俗文化的保护前景堪忧, 由于城镇化和多远文化的 侵入, 传统的苗族民俗民情逐渐被淹没, 少人遵从, 无人问津, 还有就是绝大部分苗族非物质文化遗产属于 口传身授, 自生自灭或自我陶醉的现状, 加上青年一代生 活环境的改变, 崇尚现代时髦, 对民族传统和民间艺术逐 渐丧失兴趣, 民族文化遗产大部分处于高度濒危状态。如 不采取有力措施, 抓紧进行抢救和保护, 后人们再次提起 苗族，恐仅有个民族名称而已了。

曲靖市是一个以汉族为主的新型城市, 境内世局的苗 族本来就聚集散, 人口少, 又多分散在曲靖下辖县份的山 区上, 随着城市现代化脚步的迈进, 原本平静的生活不可 避免的受到了打扰, 苗寨之间分散的地域和稀少的交流, 使他们世世代代传承下来的民族文化, 正在遭受着现代化 社会发展和多元文化意识形态的冲击, 正走向濒危的窘 境。虽然曲靖市地区政府, 开发了许多诸如少数民族节庆 节日旅游文化节和少数民族农家民俗村的旅游项目，从某
种意义上, 增强了对少数民族文化和民俗的宣传, 但是这 些相比大的社会现代化潮流, 简直是杯水车薪, 更多的还 是需要我们整个社会的关注与保护, 不要让我们本来 56 个少数民族璀璨夺目的民族传统和文化消失。

\section{6. 结论}

苗族是我国古老的少数民族之一, 在漫长的历史发展 长河里, 苗族人民在生产劳动和斗争中, 创造了辉煌灿烂 的民族文化和丰富多彩的风俗习惯, 曲靖地区世局的苗族 虽然聚集散, 人数少, 但有其自身的历史源流和民俗特性, 他的存在和发展是我们地区不可或缺的精神依托和文化 蕴涵。

\section{参考文献(References)}

[1] Chen, H, Review the history of Miao culture. Journal of Southwest University for Nationalities, July 2002.

[2] Zhang, H. w. The upper reaches of the Pearl River National Traditional introduction. Kunming: Yunnan University press, 2010, pp.45

[3] Yuan, K. Ancient myths and select, Beijing: north people's Literature Publishing House, 1979, pp.155.

[4] Yu, W. R, The soul of Taijiang Miao: Miao culture space. Haerbin: Heilongjiang people's publishing house, 2005, pp. 86. 